\title{
Research on China's Total Energy Consumption and Energy Structure
}

\section{Guan Yeqing}

Associate Professor in College of Economics and Management, Nanjing University of Aeronautics and Astronautics, Nanjing, China Phone: 86-25- 84893751; Email: nuaaynx@nuaa.edu.cn

Liu Hua

Postgraduate in College of Economics and Management, Nanjing University of Aeronautics and Astronautics, Nanjing, China Email: liuhua802901@nuaa.edu.cn

\section{Doi:10.5901/mjss.2013.v4n9p381}

\section{Abstract}

Energy and its structure play important roles in the development of economy. This paper built up GM(1,1) models for energy production and consumption in China. Then predicted and analyzed total amount of energy production and consumption in China as well as the structure of energy. The study showed that GM(1,1) model can simulate and predict the trend of the total amount of energy consumption and the structure well. In the future, the structure of energy consumption will be optimized. The proportion of coal and oil will decrease and the proportion of gas and renewable energy sources will increase in order to fill the gap.

Keyword: energy; consumption structure; GM(1,1)

\section{Introduction}

Energy is the fundamental material of importance in human society. Each major progress in human civilization accompanied with improvement and replacement of energy. History has proved that the reasonability of the structure of energy consumption is a very important index when measuring the development of economy in one country or district. For a long time, the main energy in China is coal and this results in some problems such as greenhouse effect, acid rain and other environment problems. So, on the premise of keeping a rapid economic growth, it is very important to adjust the structure of energy consumption.

Researches on energy consumption at home and abroad mainly focus on checking the relationship of energy consumption and economic development. Yu and Jin used the two step E G method put forward by Engle and Granger, proving that there is not an obvious long-term balanced co-integration relationship with American quarterly data from 1974 to 1990[1]. Stern used co-integration equation of static analysis and multivariate dynamic co-integration analysis, finding that energy has a notable effect in the change of GDP. Besides that, he determined that there is an obvious longterm co-integration equilibrium relationship of GDP, capital, manpower and energy[2,3]. Wu studied the change of the energy consumption in the progress of urbanization in China[4].Lu built up a complex system and studied energy consumption in China using a combined model[5]. Qi and Luo analyzed the economic development and energy consumption in some area, encouraged and guided that each area should cooperate with each other according to their main energy and energy efficiency and take an energy saving sustainable balanced growth way[6].Zhao studied the relationship of energy consumption and carbon emission in Shanghai[7].Wang used co-integration theory and causality test to study the co-integration and casual relationship of economic development and electricity consumption[8].Guan used structural dynamic model to study the rule of the structure of energy consumption from 1990 to 2003[9].These above researches provided many discussions for us to study how to improve the structure of energy consumption. But there is few research that focuses on predicting the energy consumption and total amount from the angle of numerical modeling. This paper used grey model to predict total amount of energy consumption and structure in China in order to provide some references to the government. 


\section{Current situation of production and consumption of energy in China}

As early as in 2004, China had become the second largest energy consumer in the world, accounting for about $11 \%$ of total world energy consumption, second only to America. In 2008, the total energy production in China has reached 2.6 billion tons of standard coal and China had become the world's largest energy producer. According to the latest statistics, China has already surpassed America as the world's largest emitter, about $21 \%$ of the world's emissions.

\subsection{Large energy consumption, can't self-sufficient}

From 2004 to 2011, the amount of energy production and consumption in China showed a trend of slow growth. In 2011, the amount of energy production reached 317987 ten thousand tons of standard coal; the amount of energy consumption reached 348002 ten thousand tons of standard coal. And there is a gap in the energy production and energy consumption, meaning that China can't autarky. Table 1 provided the total amount of energy production and energy consumption in China from 2004 to 2011.

Table 1. Total amount of energy production and energy consumption in China from 2004 to 2011 (unit: ten thousand tons of standard coal)

\begin{tabular}{lcccccccc}
\hline Year & 2004 & 2005 & 2006 & 2007 & 2008 & 2009 & 2010 & 2011 \\
\hline Energy consumption & 213456 & 235997 & 258676 & 280508 & 291448 & 306647 & 324939 & 348002 \\
Energy production & 196648 & 216219 & 232167 & 247279 & 260552 & 274619 & 296916 & 317987 \\
\hline
\end{tabular}

Analyze from economic development in China from 2004 to 2011 we can find that the growth of energy consumption and economic development in China maintains highly consistent on the whole. Correlation analysis shows that the correlation coefficient of total energy consumption and economic growth in China is 96.88\% from 2004 to 2011 (Seen in Picture 1). We can find that economic development pushes the demand of energy and energy with an average of $7.26 \%$ growth prop up an average of $16.86 \%$ economic growth in China.

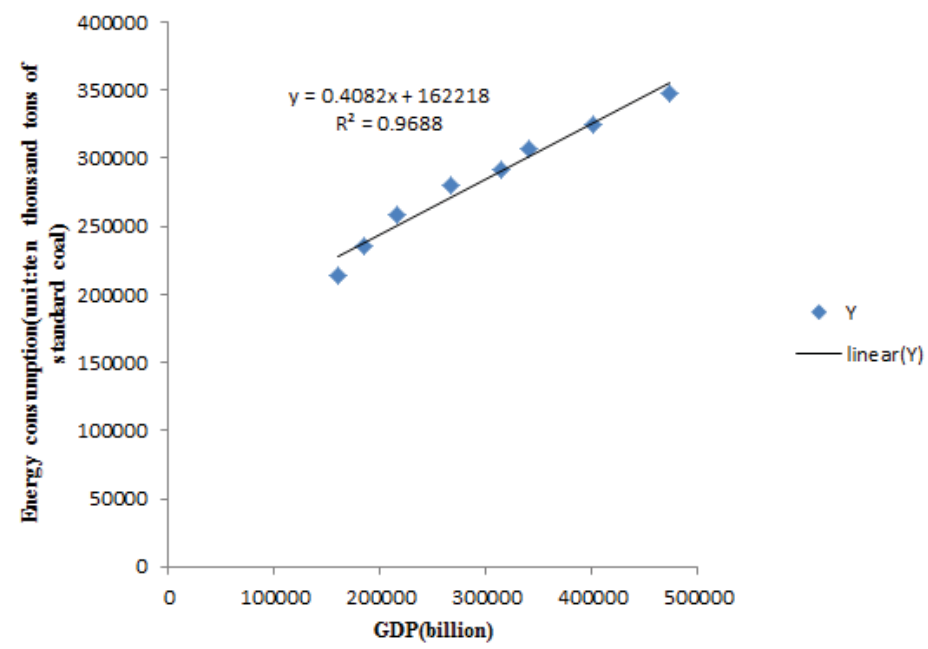

Picture 1. Relationship of energy consumption and economic development in China (2004-2011)

\subsection{Low levels of energy consumption structure}

Table 2 provided the structure of energy consumption in China. From Table 2 we can see that coal is the main energy in China, about $70 \%$ these years. Oil accounts for about $20 \%$. Coal and oil account for about $90 \%$ of total energy 
consumption and the proportion is decreasing. In 2004, they accounted for $90.8 \%$ and in 2011 87\%; gas and other energies (mainly renewable energies) accounted for a small proportion and the proportion is increasing these years.

Table 2. Structure of energy consumption in China

\begin{tabular}{lcccccccc}
\hline Year & 2004 & 2005 & 2006 & 2007 & 2008 & 2009 & 2010 & 2011 \\
\hline Coal & 69.5 & 70.8 & 71.1 & 71.1 & 70.3 & 70.4 & 68 & 68.4 \\
Oil & 21.3 & 19.8 & 19.3 & 18.8 & 18.3 & 17.9 & 19 & 18.6 \\
Gas & 2.5 & 2.6 & 2.9 & 3.3 & 3.7 & 3.9 & 4.4 & 5 \\
Other energies & 6.7 & 6.8 & 6.7 & 6.8 & 7.7 & 7.8 & 8.6 & 8 \\
\hline
\end{tabular}

\subsection{Prospects for development of renewable energy}

Since the 1980s, wind power, solar energy, biomass energy and such other technologies and industries have been developing steadily with the support of government. Small hydro, solar water heater, small wind power and other renewable energies technologies and industries have been walking in the forefront of the world. In addition, China has an abundant reserve of renewable energy resources. More than two-thirds of the total land area has rich solar energy, radiation more than 600000 joules per square centimeter, each year the earth's surface absorbs solar energy equal to about 1.7 trillion tons of standard coal of energy. Wind energy resources in China is about $0.7 \sim 1.2$ billion kilowatt, and the wind energy can be developed mainly focus on the land with land capacity reach 1.4 2.4 trillion kilowatt hours. Current available biomass resources are about 290 million tons, mainly is agricultural organic waste. Hydropower resources that can be developed are very rich, about 600 million kilowatt. The exploitable hydropower that can be developed are at least 500 million kilowatt or more and the power can provide 2.5 trillion kilowatt hour. Therefore, China has the conditions and technology potential to develop the large scale of renewable energy resource and this can provide enough energy for the future development of society and protection. We can do a lot to develop and use renewable energy.

\section{Prediction of energy consumption in China}

\subsection{Progress of solving GM(1,1) model}

Step 1: Sequence data acquisition; acquire the nonnegative sequence

$$
X^{(0)}=\left(x^{(0)}(1), x^{(0)}(2), \cdots, x^{(0)}(n)\right) \text {, and } x^{(0)}(k) \geq 0, \quad k=1,2, \cdots, n \text {; }
$$

Step 2: Sequence data accumulation generation; accumulate $X^{(0)}$ and then we get the accumulation generation $X^{(1)}$ :

$$
X^{(1)}=\left(x^{(1)}(1), x^{(1)}(2), \cdots, x^{(1)}(n)\right), x^{(1)}(k)=\sum_{i=1}^{k} x^{(0)}(i), \quad k=1,2, \cdots, n \text {; }
$$

Step 3: Mean sequence generation; according to $X^{(1)} ;$ get its mean sequence $Z^{(1)}$ :

$$
\begin{aligned}
& Z^{(1)}=\left(z^{(1)}(2), z^{(1)}(3), \cdots, z^{(1)}(n)\right), \text { and } \\
& z^{(1)}(k)=\frac{1}{2}\left(x^{(1)}(k)+x^{(1)}(k-1)\right), \quad k=2,3, \cdots, n
\end{aligned}
$$

Step 4: Parameter solution; if $\hat{a}=(a, b)^{T}$ is parameter column, and

$$
Y=\left[\begin{array}{c}
x^{(0)}(2) \\
x^{(0)}(3) \\
\vdots \\
x^{(0)}(n)
\end{array}\right], B=\left[\begin{array}{cc}
-z^{(1)}(2) & 1 \\
-z^{(1)}(3) & 1 \\
\vdots & \vdots \\
-z^{(1)}(n) & 1
\end{array}\right]
$$

Then the least squares estimate parameter of $\mathrm{GM}(1,1)$ model $x^{(0)}(k)+a z^{(1)}(k)=b$ satisfies $\hat{a}=\left(B^{T} B\right)^{-1} B^{T} Y$. 
Step 5: Time response function; according to the result of step 1 to 4 , solve the winterization equation $\frac{\mathrm{d} x^{(1)}}{\mathrm{d} t}+a x^{(1)}=b$

$$
x^{(1)}(t)=\left(x^{(1)}(1)-\frac{b}{a}\right) \mathrm{e}^{-a t}+\frac{b}{a}
$$

Step 6: Time response sequence; according to step 5, we can get the time response sequence

$$
\begin{aligned}
& \hat{x}^{(1)}(k+1)=\left(x^{(0)}(1)-\frac{b}{a}\right) \mathrm{e}^{-a k}+\frac{b}{a}, \\
& k=1,2, \cdots, n
\end{aligned}
$$

Step 7: Simulate and predict; according to the result in step 6; we can get the simulation function:

$$
\hat{x}^{(0)}(k+1)=\left(1-\mathrm{e}^{a}\right)\left(x^{(0)}(1)-\frac{b}{a}\right) \mathrm{e}^{-a k}, k=1,2, \cdots, n
$$

\subsection{Prediction of energy production and consumption in China}

Because total amount of energy consumption in China and its increase are influenced by economic development, structure of energy, structure of industry and some other factors while some factors are determined with some undetermined, we can see it as a grey system. We can build up the GM(1,1) model by some data and grasp the change trend and rule of the system, avoiding the defect of the lack of data as well as the influence of personal experience, cognition and preference. So, we can use the method to predict total amount of energy consumption in the future in China.

According to total amount of energy consumption in China from 2004 to 2011 (seen in Table 1), we build up the $\mathrm{GM}(1,1)$ model, and then get $a=-0.06, b=222087$.As a result, we get the simulation function

$$
\hat{x}^{(0)}(k+1)=228008.86 \mathrm{e}^{0.06 k}, k=1,2, \cdots, n
$$

Simulation result for detail can be seen in Table 3 . And the average relative error is $0.95 \%$.

Table 3. Simulation result of total amount of energy consumption in China (unit: ten thousand tons of standard coal)

\begin{tabular}{cccc}
\hline Year & Original value & Simulation value & Relative error \\
\hline 2004 & 213456 & 213456 & 0 \\
2005 & 235997 & 242165 & $2.61 \%$ \\
2006 & 258676 & 257201 & $0.57 \%$ \\
2007 & 280508 & 273170 & $2.62 \%$ \\
2008 & 291448 & 290130 & $0.45 \%$ \\
2009 & 306647 & 308144 & $0.49 \%$ \\
2010 & 324939 & 327276 & $0.72 \%$ \\
2011 & 348002 & 347596 & $0.12 \%$ \\
\hline
\end{tabular}

According to total amount of energy production in China from 2004 to 2011 (seen in Table 1), we build up the GM(1,1)

\begin{tabular}{|c|c|c|c|}
\hline Year & Original value & Simulation value & Relative error \\
\hline 2004 & 196648 & 196648 & 0 \\
\hline 2005 & 216219 & 216475 & $0.12 \%$ \\
\hline 2006 & 232167 & 230542 & $0.70 \%$ \\
\hline 2007 & 247279 & 245523 & $0.71 \%$ \\
\hline 2008 & 260552 & 261477 & $0.36 \%$ \\
\hline
\end{tabular}
model, and then get $a=-0.063, b=197351$. As a result, we get the simulation function

$$
\hat{x}^{(0)}(k+1)=203266.26 \mathrm{e}^{0.063 k}, k=1,2, \cdots, n
$$

Simulation result for detail can be seen in Table 4 . And the average relative error is $0.51 \%$.

Table 4. Simulation result of total amount of energy production in China (unit: ten thousand tons of standard coal) 


\begin{tabular}{llll}
2009 & 274619 & 278468 & $1.40 \%$ \\
2010 & 296916 & 296564 & $0.12 \%$ \\
2011 & 317987 & 315835 & $0.68 \%$ \\
\hline
\end{tabular}

According to the simulation result, the average relative errors of energy consumption and production are separately $0.95 \%$ and $0.51 \%$, showing that the simulation results are well. We can predict based on this, the total amount of energy consumption in China will keep increasing, the amount will reach 442299 ten thousand tons of standard coal in 2015. In the same time, the total amount of energy production will also keep increasing and will reach 406282 ten thousand tons of standard coal in 2015.

\section{Prediction of energy structure in China}

According to the proportion of energy structure in Table 2, we can build up GM(1,1) models for coal, oil ,gas and other energies and get their time sequence response function:

$$
\begin{aligned}
& \hat{x}^{(0)}(k+1)=72.034 \mathrm{e}^{0.0072 k} ; \quad k=1,2, \cdots, n \\
& \hat{x}^{(0)}(k+1)=19.5657 \mathrm{e}^{0.0098 k} ; \quad k=1,2, \cdots, n \\
& \hat{x}^{(0)}(k+1)=2.3611 \mathrm{e}^{0.1055 k} ; \quad k=1,2, \cdots, n \\
& \hat{x}^{(0)}(k+1)=6.3609 \mathrm{e}^{0.0399 k} ; \quad k=1,2, \cdots, n
\end{aligned}
$$
for detail.

According to the functions, we can predict the proportions of the energies from 2012 to 2015 , Table 5 provides this

Table 5. Proportions of energies from 2012 to 2015

\begin{tabular}{ccccc}
\hline Year & coal & oil & gas & other energies \\
\hline 2012 & $66.11 \%$ & $17.39 \%$ & $5.50 \%$ & $10.27 \%$ \\
2013 & $65.64 \%$ & $17.22 \%$ & $6.10 \%$ & $10.68 \%$ \\
2014 & $65.17 \%$ & $17.05 \%$ & $6.80 \%$ & $11.12 \%$ \\
2015 & $64.71 \%$ & $16.88 \%$ & $7.50 \%$ & $11.57 \%$ \\
\hline
\end{tabular}

From the result, we can see that the proportions of coal and oil are decreasing while gas and other energies are increasing, showing China is developing clear energy vigorously.

\section{Conclusions and discussions}

1) This paper builds up $\mathrm{GM}(1,1)$ models for energy production and consumption in China and then use the models to simulate and predict. The study shows GM(1,1) models can simulate and predict the total amount of energy production and consumption in China well.

2) This paper builds up $\mathrm{GM}(1,1)$ model for the proportion of each energy, and then predict the change trend of the proportion of energy consumption. In the future, the proportions of coal and oil will keep decreasing while gas and other energy will increase.

3) In order to realize the prediction result and improve the structure of energy consumption, China should implement energy conservation and emissions reduction and sustainable development actively, and develop gas and renewable energies while decreasing the proportion of coal and oil.

\section{References}

Yu Eden S, Jang C. Jin, Co integration Tests of Energy Consumption, Income and employment. Resources and Energy, 1992, 14(3): 259-266.

Stern D.I., Energy Use and Economic Growth in the USA: a Multivariate Approach, Energy Economics, 1993, 15(1): 137-150.

Stern D.I., A Multivariate Co integration Analysis of the Role of Energy in the US Macro economy, Energy Economics, 2000, 22(2): 267283.

Q.S. Wu, J.H. Cheng, H. Wang, Change of Energy Consumption with the Process of Industrialization in China [J].China Industrial Economy, 2005,(04):30-37. 
Lu Q, Gu P L, Qiu S M. The Construction and Application of Combination Forecasting Model in Chinese Energy Consumption System [J]. Systems Engineering-Theory \& Practice, 2003,23(03):24-30.

Lu Q, Gu P L, Qiu S M. The Construction and Application of Combination Forecasting Model in Chinese Energy Consumption System [J]. Systems Engineering-Theory \& Practice, 2003,23(03):24-30.

Zhao M, Zhang W G, Yu L Z. Carbon Emissions from Energy Consumption in Shanghai City [J]. Research of Environmental Sciences, 2009,22(08):984-989.

Wang H P, Tian P, Jin P. The Study of the Relationship Between China's Energy Consumption and Economics Growth Based on Time Varying Parameter Model [J].Application of Statistics and Management, 2006,25(3):253-258.

Guan W H, Gu C L, Lin Z S. Study on the Change of Energy Consumption Structure in China [J]. Journal of Natural Resources, 2006, 21(3):401-407. 